\title{
Influence of Statins locally applied from orthopedic implants on osseous integration
}

\author{
Stephan Pauly ${ }^{1 * \dagger}$, David A Back ${ }^{1,3 \dagger}$, Kathrin Kaeppler ${ }^{1,4}$, Norbert P Haas ${ }^{1}$, Gerhard Schmidmaier ${ }^{4}$ \\ and Britt Wildemann ${ }^{1,2}$
}

\begin{abstract}
Background: Simvastatin increases the expression of bone morphogenetic protein 2 (BMP-2) in osteoblasts, therefore it is important to investigate the influence of statins on bone formation, fracture healing and implant integration. The aim of the present study was to investigate the effect of Simvastatin, locally applied from intramedullary coated and bioactive implants, on bone integration using biomechanical and histomorphometrical analyses.
\end{abstract}

Methods: Eighty rats received retrograde nailing of the femur with titanium implants: uncoated vs. polymer-only (poly(D,L-lactide)) vs. polymer plus drug coated (either Simvastatin low- or high dosed; "SIM low/ high"). Femurs were harvested after 56 days for radiographic and histomorphometric or biomechanical analysis (push-out).

Results: Radiographic analysis revealed no pathological findings for animals of the control and SIM low dose group. However, $n=2 / 10$ animals of the SIM high group showed osteolysis next to the implant without evidence of bacterial infection determined by microbiological analysis. Biomechanical results showed a significant decrease in fixation strength for SIM high coated implants vs. the control groups (uncoated and PDLLA). Histomorphometry revealed a significantly reduced total as well as direct bone/implant contact for SIM high- implants vs. controls (uncoated and PDLLA-groups). Total contact was reduced for SIM low vs. uncoated controls. Significantly reduced new bone formation was measured around SIM high coated implants vs. both control groups.

Conclusions: This animal study suggests impaired implant integration with local application of Simvastatin from intramedullary titanium implants after 8 weeks when compared to uncoated or carrier-only coated controls.

Keywords: Statins, Simvastatin, Implant integration, BMP, Local application

\section{Background}

The increasing number of primary and revision surgeries following orthopaedic implant application suggests the need for a durable osseous integration. Optimal osseointegration depends on the formation of new bone around orthopaedic implants, which may be stimulated by osteoinductive agents.

One safe [1] and promising substance group for this aim are the statins, where were primarily developed to inhibit cholesterol biosynthesis [2] and reduce its plasma levels [3]. Besides other pleiotropic effects [4,5], Simvastatin furthermore stimulates bone formation in a human

\footnotetext{
*Correspondence: stephan.pauly@charite.de

${ }^{\dagger}$ Equal contributors

'Julius Wolff Institut, Center for Musculoskeletal Surgery, Charité Universitaetsmedizin Berlin, Berlin, Germany

Full list of author information is available at the end of the article
}

osteoblast cell line (MG-63) via increased expression of bone morphogenetic protein (BMP-2) [6]. BMP-2 is one of the most potent growth factors targeting bone formation in vivo [7], which stimulates osteoblast differentiation and -proliferation [8-10].

With systemic [11-14] or local delivery of statins to the bone from biodegradable carriers or percutaneous application forms, bone formation and fracture healing were improved in several experimental investigations [15-22].

Statins were also shown to improve implant integration following arthroplastic surgery. Although there have been multiple studies using systemic administration [11,23-25], only a few studies have investigated local application of statin-containing gels or microspheres and their effect on implant-bone integration [26-28]. In summary, combining the bone anabolic effect of Simvastatin with other local

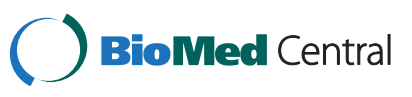


drug application techniques is a promising approach. Local application seems to be a reasonable strategy, as statins target liver metabolism and are poorly distributed to bone due to first pass elimination [29]. Furthermore, local application helps prevent systemic side effects of drugs.

Hence, it was the aim of the present study to investigate the effect of Simvastatin, locally applied in a biodegradable Poly(D,L-lactide) coating from intramedullary implants [30], on bone integration using biomechanical and histomorphometrical analyses.

We hypothesized that Simvastatin would improve histomorphometrical and biomechanical implant integration when compared to uncoated or carrier onlycoated devices.

\section{Results}

There were no differences in body temperature and -weight between the groups over the experimental time period. None of the animals showed evidence of local or systemic infection throughout the experimental period.

After 56 days at the $x$-ray control, no radiographic implant dislocation was observed (Figure 1). However, $n=2 / 20$ animals of the SIM high-group showed osteolysis around the implants (Figure 2) and $n=1 / 20$ animal from both the PDLLA and SIM high group had broadened medullary canals. However, microbiological analysis of these affected femurs showed no evidence of bacterial infections.

Calculated strength of fixation was highest for uncoated implants when compared to all other control and experimental groups. Fixation of SIM high coated implants was significantly weaker than with uncoated- $(\mathrm{p}=0.002)$ or PDLLA-coated implants ( $\mathrm{p}=0.005$, Figure 3 ).

Histomorphometrical analysis with regard to total bone/implant contact showed only marginal differences between the control groups (uncoated, PDLLA-coated, Figure 4). However, lower results were detected for both experimental groups, reaching level of significance for SIM high when compared to both control groups (minus $46.0 \%$ and $32.8 \%$, respectively, $\mathrm{p}<0.001$ ) and for SIM low vs. uncoated controls $(\mathrm{p}=0.006)$.

Neither direct nor indirect bone/implant contact differed significantly between uncoated and PDLLAcoated implants. In terms of direct contact, SIM high results were significantly decreased when compared to both control groups (vs. uncoated: $\mathrm{p}=0.001$; vs. PDLLA: $\mathrm{p}=0.006$; Figure 4).

Indirect contact was highest in the uncoated and PDLLA-coated groups. Both SIM coated groups had lower values than the controls, differing significantly
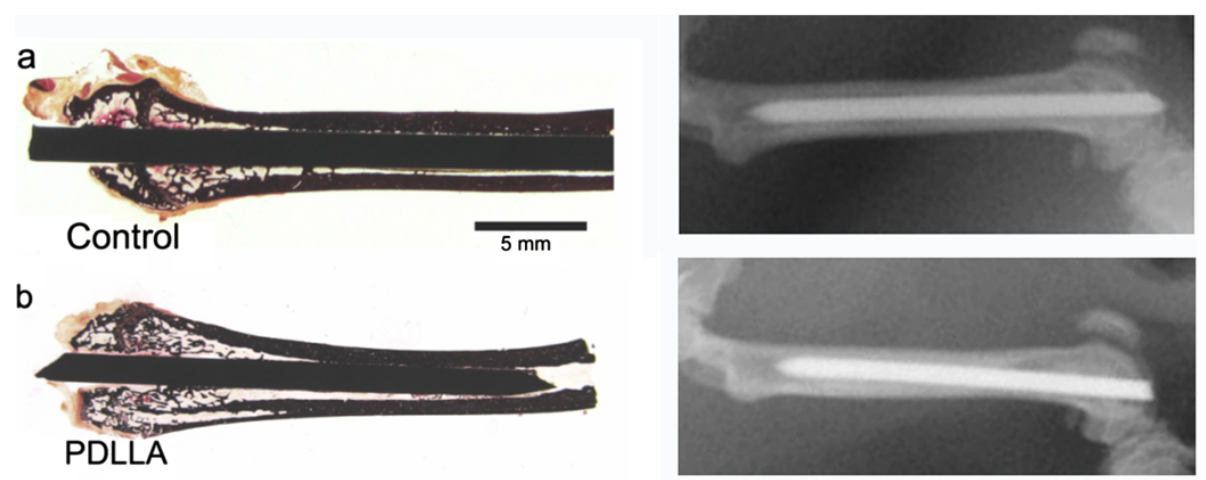

C
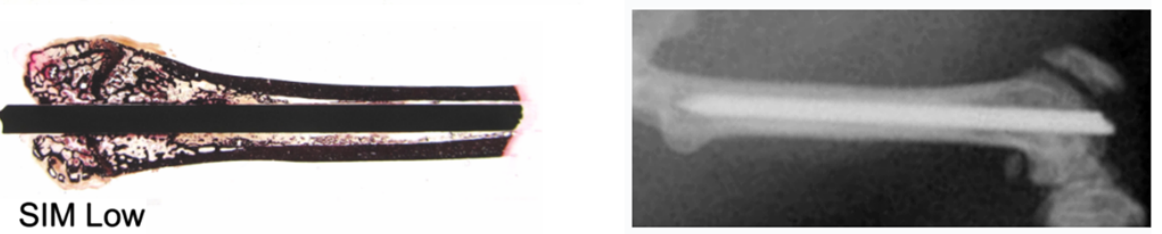

d
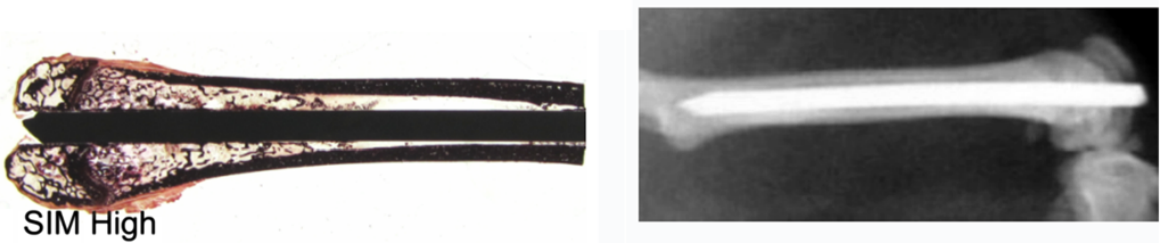

Figure 1 Histomorphometric overview and x-ray after 56 days, for animals from a) uncoated group, b) PDLLA, c) SIM low and d) SIM high. No macroscopic differences were obvious between all 4 groups with regard to implant integration, osteolysis, ectopic bone formation or implant loosening. 


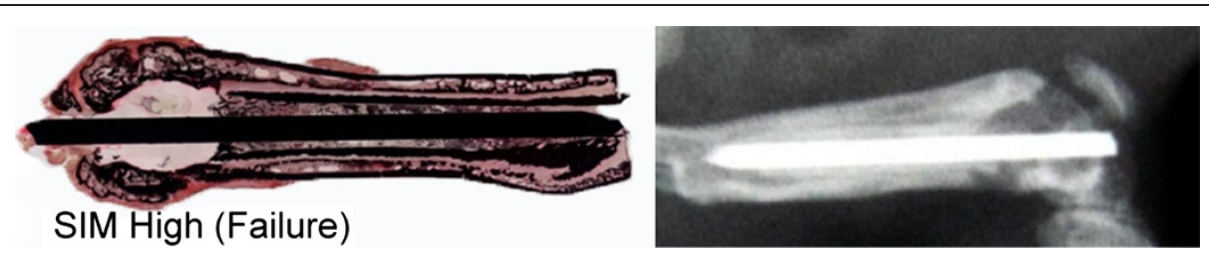

Figure 2 Microscopic and radiographic findings in one (out of $n=2 / 20$ ) SIM high-treated femur after 56 days, showing osteolysis around the implant. Bacterial infection was ruled out by means of microbiological diagnostics.

between the PDLLA and SIM high group (minus 51.0\%; $\mathrm{p}=0.004$, Figure 4).

Assessment of newly formed bone around the implants revealed significant reduction for the groups PDLLA ( $\mathrm{p}=$ 0.002 ) and SIM low and -high ( $p<0.001$, respectively) when compared to uncoated controls (Figure 4). SIM high implants showed significantly less surrounding new bone than PDLLA-coated implants $(\mathrm{p}=0.002)$.

\section{Discussion}

The present findings suggest impaired implant integration with local application of Simvastatin from intramedullary titanium implants after 8 weeks when compared to uncoated or carrier-only coated controls.

Though the two cases of radiographic osteolysis around the implant occured in the histomorphometric group, biomechanical stability was significantly weaker for SIM high when compared to uncoated and carrier-only coated implants. Histomorphometry confirmed a significant reduction in total bone/implant contact, (in-)direct contact and new bone formation for the experimental groups when compared to the control groups.

In summary, the hypothesis of the present paper with regard to improved implant integration must be rejected for both experimental groups.

The question arises why bone integrational processes deteriorated under Simvastatin exposure when compared to controls. One potential obvious explanation, intramedullary infections of the femurs, was ruled out since no bacteria were identified after microbiological analysis over 14 days.

Another possible reason for the adverse effects might be the PDLLA-coating itself. However, this polymer was previously shown to be biocompatible, mechanically stable [30] and a reproducibly degradable carrier to locally deliver agents to the bone, without evidence of osteolysis [20,31-34]. Furthermore, the PDLLA-group showed (significantly) superior biomechanical, histomorphometric and radiographic properties when compared to the experimental groups. Thus, PDLLA is likely not the reason for the deteriorated bone integration, even

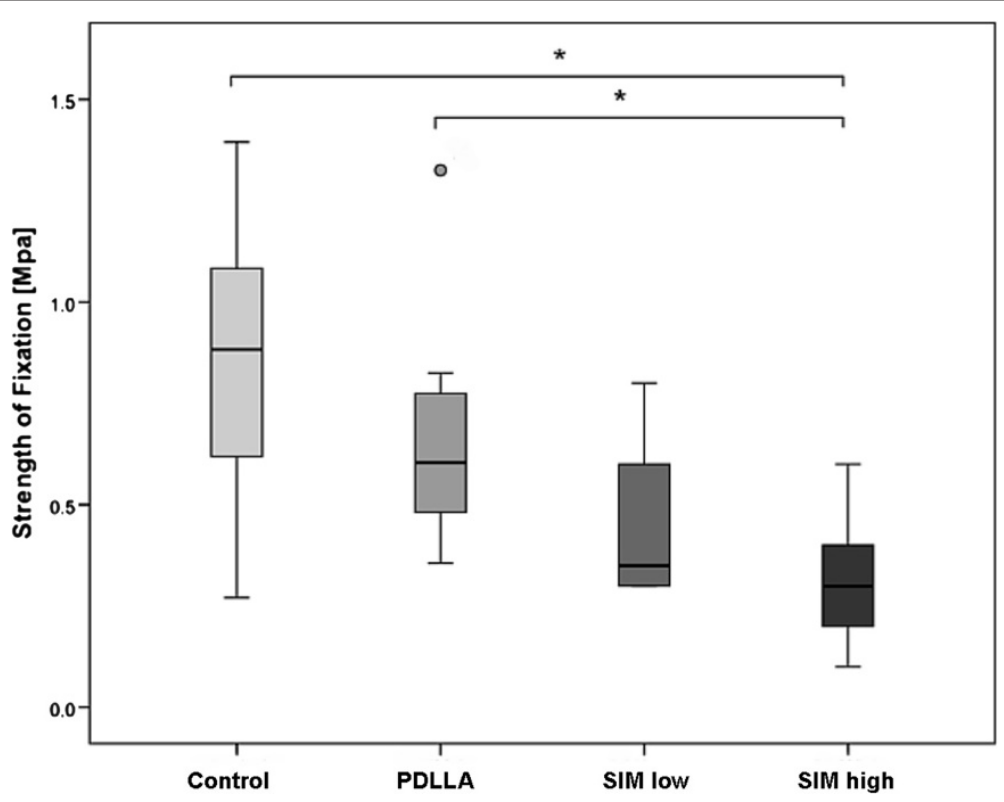

Figure 3 Biomechanical fixation strength of SIM high coated implants was significantly weaker than with uncoated- $(p=0.002)$ or PDLLA-coated implants $(p=0.005)(*)$. 

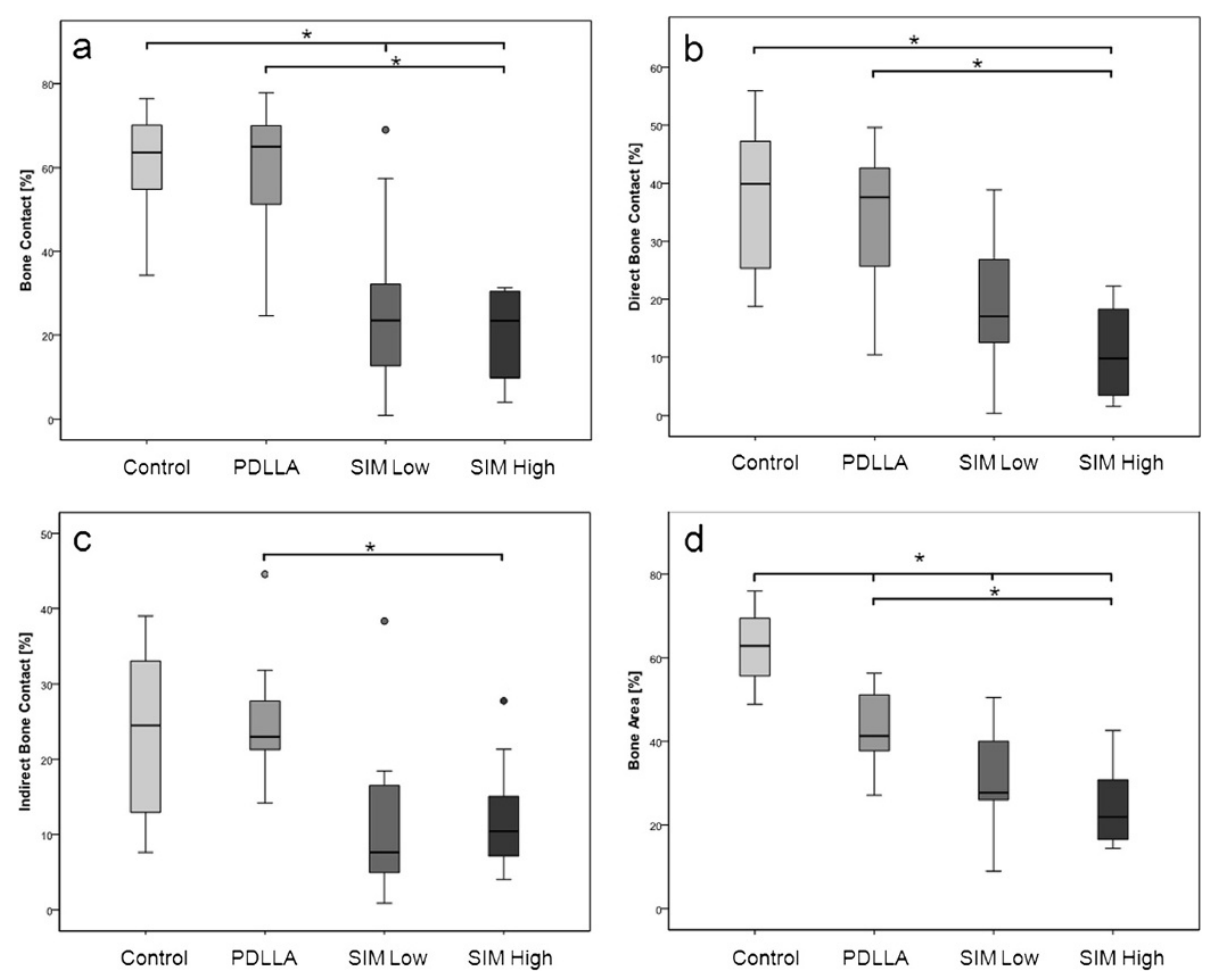

Figure 4 a) Histomorphometric analysis. Total bone/implant contact was significantly decreased between the uncoated control and both experimental groups (SIM high: $p<0.001$; SIM low: $p=0.006)$ as well as between PDLLA and SIM high $(p<0.001)\left(^{*}\right)$. b) Direct bone/implant contact showed significant differences between SIM high and both control groups (vs. uncoated: $p=0.001$; vs. PDLLA: $p=0.006)(*)$. c) Indirect bone/implant contact was reduced for both SIM coated groups, differing significantly between the PDLLA and SIM high group $(p=0.004)(*)$. d) Newly formed bone (within a $0.3 \mathrm{~mm}$ range around the implants) was significantly reduced between uncoated controls and all other groups (vs. PDLLA: $p=0.002$; vs. SIM low and - high: $p<0.001$, respectively), as well as between PDLLA and SIM high implants $(p=0.002)(*)$.

though its biomechanical stability was slightly inferior when compared to uncoated controls.

Another possible reason for the lack of osseointegration may have been the drug dose used, since dose-dependent effects of statins on bone metabolism were suggested due to differing sensitivity of osteoblasts and osteoclasts. Bone resorption and formation were elevated with high-dose Simvastatin while low-dose SIM decreased formation and increased bone resorption [35]. The present results seem contrary since SIM high rather than SIM low had bone catabolic effects and neither exerted bone anabolic effects. The dose-dependent, bone-anabolic effect of a comparable SIM high-dose was previously shown to have a similar effect to that of BMP-2 in a rat fracture model [20]. Additionally, one other failure option is the type of the incorporated drug. However, the identical substance and coating technique were successfully investigated previously [20]. Several other experimental studies confirmed beneficial effects of statins on fracture healing using different local application approaches $[18,19,21,22]$. In addition, statins improved defect regeneration when locally applied in cranial/ mandibular bone defect models without metal implants [15-17,36]. These studies used absorbable collagen and gelatin sponges or injections for drug delivery which are prone to dissolve at the site of application. A femoral defect model with local small molecule drug delivery (but no metal implant) revealed bisphosphonates significantly improved bone formation while lovastatin did not [37]. Piskin et al. demonstrated Simvastatinloaded electrospun nanofibers enhanced bone mineralization (histological and micro-CT analysis) [38]. Even though the same drug was used, the different dosage and the use of the polymer caprolactone represent different approaches than in the present setting, hence impede comparability.

In contrast to fracture- and bone defect healing, implant integration was investigated presently. In this regard, different studies investigated the effect of local statin application. A similar rodent model was utilized by Moriyama et al. who observed improved tibial implant integration dose-dependently after 7-14 days of local fluvastatin-release from a PGA-coating [26]. In contrast to the present findings, their higher-dosed group $(2.5 \mathrm{mg} / \mathrm{ml})$ showed the best results in terms of bone formation and push-out strength. The short observational period of 7 or 14 days may be one reason for 
different results when compared to the present 56 day period. Further distinctions to the present study are the chosen type of carrier and the incorporated drug Fluvastatin (vs. Simvastatin), although both are lipophilic, penetrate cell membranes and enhance osteogenesis. These authors later investigated injectable PGA-gel around tibia implants in rodents and found similar results [28]. They observed a significant decrease in implant integration at one week comparable to the present results after 56 days. However, stability recovered and significantly increased after 14 and 28 days, respectively. Nevertheless, injected gel or mobile nanoparticles may dissolve from the intramedullary destination, while solid bioactive implant coatings may reduce this effect.

Other experimental studies reported on improved orthopedic implant integration in animals even under systemical exposure to statins, administered orally [23], percutaneously $[24,27]$ or intraperitoneally $[11,25]$. Effects were observed with up to $10-50 \mathrm{mg} / \mathrm{kg}$ bodyweight, far exceeding the statin dose rates applied in humans, while the equivalent dose used in humans was ineffective [25]. Hence, systemical application does not seem to be useful for improved implant integration with normal human drug doses. Even though one observational clinical study reported on reduced risk of hip implant revision, deep infection and aseptic loosening among statin users under normal dose rates [39], no direct conclusion on the drug was feasible. It was suggested that statin-users in general might show a more health oriented behaviour (i.e. medication or rehabilitation compliance). One prospectively randomized clinical study found no effect on bone healing between low Simvastatin-intake $(20 \mathrm{mg} / \mathrm{d}$ orally) and placebo [40].

Since less than $5 \%$ of an oral statin dose reaches the circulation due to hepatic first pass elimination [29], systemical application requires rather high drug doses. Targeted, local application of drugs from bioactive carrier polymers seems more efficient and may help to improve drug availability within the bone while lowering necessary drug doses, hence preventing systemic side effects.

As another potential limitation of this study, the $o b$ servation period of eight weeks may be inappropriate to observe differences in implant integration since other authors observed effects of statins with this regard after 7-30 days [11,25-28]. During fracture healing, beneficial effects were reported after 5-14 days of local statin exposure to the fracture site $[18,21,22]$, suggesting that statins cause a delayed onset of endogenous BMP-2 production [20]. Mundy et al. reported on a quick BMP-2 response to statins within 3-5 days in vivo and in vitro [6] while other authors found improved implant integration after 42-84 days following high systemical doses of Simvastatin $[23,24]$.
After 8 weeks, remodeling "back to normal" may occur and initial improvements in implant integration may vanish over time. However, mid- and long term data are important with regard to prosthetic implant integration in humans.

Nevertheless, the timepoint does not explain the osteolysis in two SIM high coated animals.

Even though the current results are discouraging with regard to Simvastatin, local application via biocompatible, stable drug-delivering polymers [30] seems beneficial since no manipulations or injections to the bone are necessary. Previous studies revealed that incorporation of several bioactive agents (such as BMP-2, Zolendronate, Simvastatin) into the PDLLA-coating of bone implants improves fracture healing and implant integration experimentally [20,31-34].

\section{Conclusions}

This animal study suggests impaired implant integration under local application of Simvastatin from intramedullary titanium implants after 8 weeks when compared to uncoated or carrier-only coated controls.

\section{Methods}

\section{Coating technology and growth factors}

Titanium Kirschner wires ("K-wires", Diameter $1.4 \mathrm{~mm}$ ) were coated with Poly(D,L-lactide), PDLLA (Boehringer, Ingelheim, Germany), differing in the substance incorporated: uncoated, PDLLA, PDLLA with low-dose Simvastatin $(5.5 \mu \mathrm{g} / \mathrm{implant}$, SIM low) or with high-dose Simvastatin (90 $\mu \mathrm{g} / \mathrm{implant,}$ SIM high). A dip coating technique was utilized which was described in more detail earlier [30].

\section{Animals and surgery}

Approval was obtained from the local Animal Experimentation Ethics Committee. According to the 3R concept [41], animals of the control groups (uncoated and PDLLA) were shared with another experimental osseointegration study (data not shown here) in order to reduce the total number of animals.

Eighty female Sprague-Dawley-Rats (mean age: 6 months, mean body weight: 260 g; Harlan-Winkelmann, Germany) were used in the experiments. Twenty animals were randomly assigned to each of the four study groups ( $\mathrm{n}=10$ specimen for biomechanical and histomorphometric analysis, respectively).

Animals were sedated with Isoflurane (Forene) and intraperitoneal anesthesia using a mixture of ketamine hydrochlorid (100 mg/mL; $80 \mathrm{mg} / \mathrm{kg}$ body weight) and $2 \%$ xylazine ( $12 \mathrm{mg} / \mathrm{kg}$ body weight).

After shaving the right hind leg, a $3 \mathrm{~mm}$ longitudinal incision was made. Subsequently, the intercondylar notch of the femur was opened carefully with a $1.2 \mathrm{~mm}$ 
hand drill and the respective implant was inserted into the medullar cavity in a retrograde direction. The aimed proximal position of the implant next to the greater trochanter was controlled via fluoroscopy. Finally, the remaining extending part of the implant was cut and skin was sutured.

With regard to pain relief, all rats received buprenorphine (Temgesic $^{\circledR}, 0.05 \mathrm{mg} / \mathrm{kg}$ ) subcutaneously for two days.

Wounds were assessed daily for clinical signs of infections. Body weight and temperature were documented during the experimental period. Digital radiographs in two planes were obtained at the time of surgery and euthanasia.

After 56 days, animals of all groups were sacrificed. The operated femurs were dissected of soft tissues and ten femurs per group were submitted for either biomechanical or histological analysis. Bones presenting with macroscopic or radiographic signs of infection (i.e. redness, swelling or secretion around the femoral approach; osteolysis around the implant) underwent sterile swabs with subsequent culture on blood agar plates. Each 24 hours of incubation time, plates were analyzed for growth of either aerobic or anaerobic bacteria over 14 days.

\section{Biomechanical testing}

Implants were exposed $3 \mathrm{~mm}$ proximally and distally in each femur after careful preparation and then embedded with bone cement (Heraeus-Kulzer, Wehrheim, Germany) in a push-out device [32]. Subsequently, a material testing device (Zwick 1455, Ulm, Germany) applied a constant linear propulsion $(\mathrm{v}=2 \mathrm{~mm} / \mathrm{min})$ to the implanted $\mathrm{K}$ wire. The peak force to loosen the implant was documented for calculating the implant-bone strength. This maximum force was normalized to the total bone- implant contact area in order to minimize variation between push-out forces due to varying bone or implant length [32]: Strength of fixation $\sigma_{\mathrm{u}}=\mathrm{F}_{\max } / \pi \mathrm{RH}\left[\sigma_{\mathrm{u}}\right.$ : strength of fixation (Mpa), $F_{\max }$ : initial push-out force $(\mathrm{N}), \mathrm{D}$ : implant diameter $(\mathrm{mm}), \mathrm{H}$ : Bone length $(\mathrm{mm})]$.

\section{Histomorphometry}

After fixation of the bones in $10 \%$ normal buffered formaldehyde for 2 days, dehydration in ascending concentrations of ethanol and undecalcified embedding in methylmethacrylate (Technovit 7200, Heraeus, Wehrheim, Germany) followed.

Specimens were ground (Exakt, Norderstedt, Germany) until implants appeared in full length with maximum diameter. The bottom areas were glued to microscope slides, cut into $300 \mu \mathrm{m}$ sections with a diamond band saw (Exakt, Norderstedt, Germany) and then ground to $80 \mu \mathrm{m}$. Different stainings were used, including Safranin-O and silvering/van Kossa (for mineralized tissues). Histological parameters were assessed using an image analysis system (Axioskop 40, Carl Zeiss, Goettingen, Germany). Within the region of interest (ROI, definition: virtual line of 13.7 $\mathrm{mm}$ starting from the nutrient foramen [42]), direct and indirect bone/implant contact were determined with an analyzing software (AxioVision 4.7, Carl Zeiss, Jena, Germany). Direct bone contact was defined as trabecular bone adjacent to the implant surface and indirect contact when a gap existed between the implant and bone. The ratio of direct-, indirect and total bone/implant contact of both cortices within the ROI was calculated. Finally, new bone formation was determined as trabecular mass within a $0.3 \mathrm{~mm}$ region on both sides of the implant inside of the ROI, normalized to the total space of this area (Figure 5).

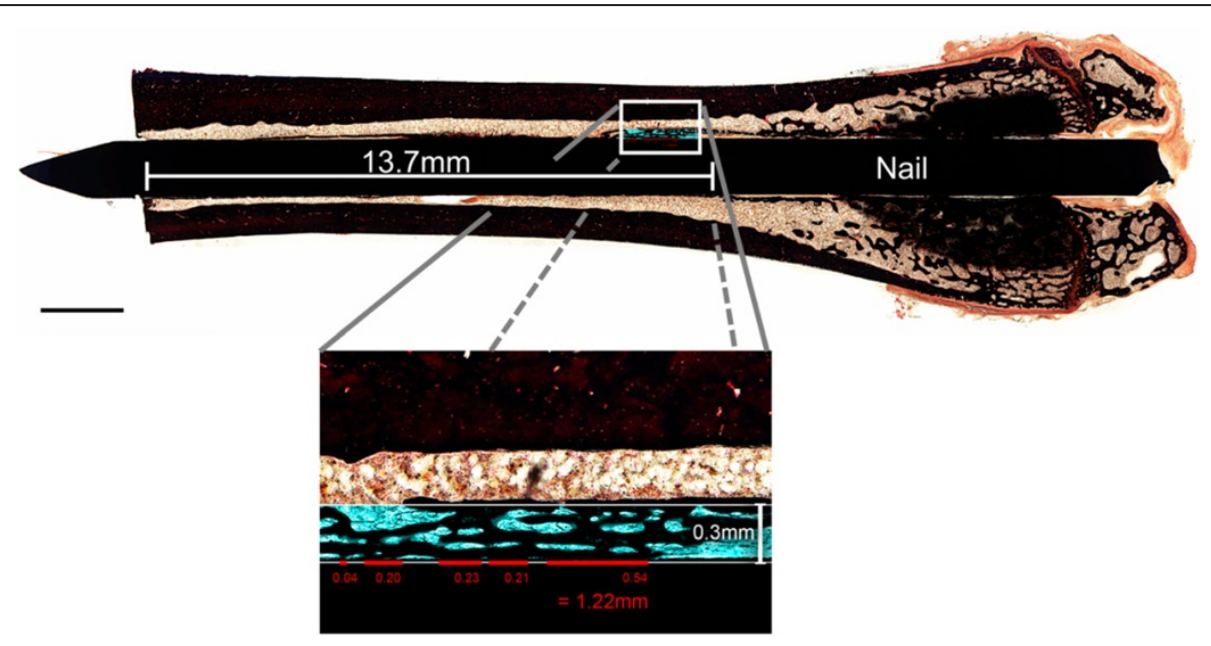

Figure 5 Histological samples were analyzed following a $13.7 \mathrm{~mm}$ line (from the nutrient foramen to the distal femur) to determine bone/implant contact and new bone formation, within a $0.3 \mathrm{~mm}$ region of interest, on both sides of the implant [42]. 


\section{Statistics}

All animals were randomized in a blinded manner for histological or biomechanical investigation. Comparison of biomechanical and histomorphometrical data was performed using Kruskal-Wallis and Mann-Whitney Test. Tests were controlled for multiple comparison using Bonferroni-Holm correction. Statistical differences were defined at the 95\% confidence level. Statistical software (SPSS release 14.0, SPSS, Inc., Chicago, IL) was used for evaluation.

\section{Abbreviations}

BMP: Bone Morphogenetic Protein; PDLLA: Poly(D,L-lactide); ROI: Region of interest; SIM: Simvastatin

\section{Competing interests}

All authors confirm that there are no conflicts of interest associated with this publication and there has been no financial support for this work that could have influenced its outcome. Financial support was provided by non-profit organizations exclusively (BMBF, Berlin Brandenburg Center for Regenerative Therapies/BCRT)

We declare that this manuscript is original, has not been published before and is not currently being considered for publication elsewhere. It has been read by all authors and each of the authors is convinced that the manuscript represents honest work.

\section{Authors' contributions}

SP participated in animal experiments, analyzed data and wrote the manuscript. DB carried out all animal operations and participated in the manuscript. KK performed histologic and biomechanical testings and statistical analysis. NH conceived of the study. GS conceived of the study, and participated in its design and coordination. BW conceived of the study, developed its design and critically revised the manuscript. All authors read and approved the final manuscript.

\section{Acknowledgements}

The present study was financially supported by BMBF, Berlin Brandenburg Center for Regenerative Therapies (BCRT).

The authors thank Lisa Rommel und Christine Kratzel for project support and Dr. Bettina Willie for proofreading the manuscript.

\section{Author details}

'Julius Wolff Institut, Center for Musculoskeletal Surgery, Charité Universitaetsmedizin Berlin, Berlin, Germany. ${ }^{2}$ Berlin-Brandenburg Center for Regenerative Therapies, Charité Universitaetsmedizin Berlin, Berlin, Germany. ${ }^{3}$ Department of Orthopedics and Traumatology, German Armed Forces Hospital Berlin, Berlin, Germany. ${ }^{4}$ Department of Orthopedic and Trauma Surgery, University of Heidelberg, Heidelberg, Germany.

Received: 17 January 2012 Accepted: 15 October 2012

Published: 26 October 2012

\section{References}

1. Armitage J: The safety of statins in clinical practice. Lancet 2007 370(9601):1781-1790.

2. Goldstein $J$, Brown MS: Regulation of the mevalonate pathway. Nature 1990, 343(6257):425-430.

3. LaRosa JC, He J, Vupputuri S: Effect of statins on risk of coronary disease a meta-analysis of randomized controlled trials. JAMA 1999 282(24):2340-2346.

4. Ridker PM, Rifai N, Pfeffer MA, Sacks F, Braunwald E: Long-term effects of pravastatin on plasma concentration of C-reactive protein. The Cholesterol and Recurrent Events (CARE) Investigators. Circulation 1999, 100(3):230-235.

5. Weis M, Heeschen C, Glassford AJ, Cooke JP: Statins have biphasic effects on angiogenesis. Circulation 2002, 105(6):739-745.
6. Mundy G, Garrett R, Harris S, Chan J, Chen D, Rossini G, Boyce B, Zhao M, Gutierrez G: Stimulation of bone formation in vitro and in rodents by statins. Science 1999, 286(5446):1946-1949.

7. Wang EA, Rosen V, D'Alessandro JS, Bauduy M, Cordes P, Harada T, Israel DI, Hewick RM, Kerns KM, LaPan P, et al: Recombinant human bone morphogenetic protein induces bone formation. Proc Natl Acad Sci USA 1990, 87(6):2220-2224

8. Wozney JM, Rosen V, Celeste AJ, Mitsock LM, Whitters MJ, Kriz RW, Hewick RM, Wang EA: Novel regulators of bone formation: molecular clones and activities. Science 1988, 242(4885):1528-1534.

9. Wang EA, Israel DI, Kelly S, Luxenberg DP: Bone morphogenetic protein-2 causes commitment and differentiation in $\mathrm{C} 3 \mathrm{H} 10 \mathrm{~T} 1 / 2$ and $3 \mathrm{~T} 3$ cells. Growth Factors 1993, 9(1):57-71.

10. Maeda T, Matsunuma A, Kawane T, Horiuchi N: Simvastatin promotes osteoblast differentiation and mineralization in MC3T3-E1 cells. Biochem Biophys Res Commun 2001, 280(3):874-877.

11. Ayukawa Y, Okamura A, Koyano K: Simvastatin promotes osteogenesis around titanium implants. Clin Oral Implants Res 2004 15(3):346-350.

12. Gutierrez GE, Lalka D, Garrett IR, Rossini G, Mundy GR: Transdermal application of lovastatin to rats causes profound increases in bone formation and plasma concentrations. Osteoporos Int 2006, 17(7):1033-1042.

13. Skoglund B, Forslund C, Aspenberg P: Simvastatin improves fracture healing in mice. J Bone Miner Res 2002, 17(11):2004-2008.

14. Gutierrez GE, Edwards JR, Garrett IR, Nyman JS, McCluskey B, Rossini G, Flores A, Neidre DB, Mundy GR: Transdermal lovastatin enhances fracture repair in rats. J Bone Miner Res 2008, 23(11):1722-1730.

15. Wong RW, Rabie AB: Statin collagen grafts used to repair defects in the parietal bone of rabbits. Br J Oral Maxillofac Surg 2003, 41(4):244-248,

16. Ozec I, Kilic E, Gumus C, Goze F: Effect of local simvastatin application on mandibular defects. J Craniofac Surg 2007, 18(3):546-550.

17. Lee Y, Schmid MJ, Marx DB, Beatty MW, Cullen DM, Collins ME, Reinhardt RA: The effect of local simvastatin delivery strategies on mandibular bone formation in vivo. Biomaterials 2008, 29(12):1940-1949.

18. Skoglund B, Aspenberg P: Locally applied Simvastatin improves fracture healing in mice. BMC Musculoskelet Disord 2007, 8:98.

19. Garrett IR, Gutierrez GE, Rossini G, Nyman J, McCluskey B, Flores A, Mundy GR: Locally delivered lovastatin nanoparticles enhance fracture healing in rats. J Orthop Res 2007, 25(10):1351-1357.

20. Pauly S, Luttosch F, Morawski M, Haas NP, Schmidmaier G, Wildemann B: Simvastatin locally applied from a biodegradable coating of osteosynthetic implants improves fracture healing comparable to BMP-2 application. Bone 2009, 45(3):505-511.

21. Wang JW, Xu SW, Yang DS, Lv RK: Locally applied simvastatin promotes fracture healing in ovariectomized rat. Osteoporos Int 2007, 18(12):1641-1650.

22. Serin-Kilicoglu S, Erdemli E: New addition to the statin's effect. J Trauma 2007, 63(1):187-191.

23. Du Z, Chen J, Yan F, Xiao Y: Effects of Simvastatin on bone healing around titanium implants in osteoporotic rats. Clin Oral Implants Res 2009, 20(2):145-150

24. Basarir K, Erdemli B, Can A, Erdemli E, Zeyrek T: Osseointegration in arthroplasty: can simvastatin promote bone response to implants? Int Orthop 2009, 33(3):855-859.

25. Ayukawa Y, Ogino Y, Moriyama Y, Atsuta I, Jinno Y, Kihara M, Tsukiyama Y, Koyano K: Simvastatin enhances bone formation around titanium implants in rat tibiae. J Oral Rehabil 2010, 37(2):123-130.

26. Moriyama Y, Ayukawa Y, Ogino Y, Atsuta I, Koyano K: Topical application of statin affects bone healing around implants. Clin Oral Implants Res 2008, 19(6):600-605

27. Masuzaki T, Ayukawa Y, Moriyama Y, Jinno Y, Atsuta I, Ogino Y, Koyano K: The effect of a single remote injection of statin-impregnated poly (lactic-co-glycolic acid) microspheres on osteogenesis around titanium implants in rat tibia. Biomaterials 2010, 31(12):3327-3334.

28. Moriyama Y, Ayukawa Y, Ogino Y, Atsuta I, Todo M, Takao Y, Koyano K Local application of fluvastatin improves peri-implant bone quantity and mechanical properties: a rodent study. Acta Biomater 2010, 6(4):1610-1618.

29. Bellosta S, Ferri N, Bernini F, Paoletti R, Corsini A: Non-lipid-related effects of statins. Ann Med 2000, 32(3):164-176. 
30. Schmidmaier G, Wildemann B, Stemberger A, Haas NP, Raschke M: Biodegradable poly( $D$, L-lactide) coating of implants for continuous release of growth factors. J Biomed Mater Res 2001, 58(4):449-455.

31. Schmidmaier G, Wildemann B, Cromme F, Kandziora F, Haas NP, Raschke M: Bone morphogenetic protein-2 coating of titanium implants increases biomechanical strength and accelerates bone remodeling in fracture treatment: a biomechanical and histological study in rats. Bone 2002, 30(6):816-822.

32. Schmidmaier G, Wildemann B, Schwabe P, Stange R, Hoffmann J, Sudkamp $N P$, Haas NP, Raschke M: A new electrochemically graded hydroxyapatite coating for osteosynthetic implants promotes implant osteointegration in a rat model. J Biomed Mater Res 2002, 63(2):168-172.

33. Wildemann B, Bamdad P, Holmer C, Haas NP, Raschke M, Schmidmaier G: Local delivery of growth factors from coated titanium plates increases osteotomy healing in rats. Bone 2004, 34(5):862-868.

34. Greiner SH, Wildemann B, Back DA, Alidoust M, Schwabe P, Haas NP, Schmidmaier G: Local application of zoledronic acid incorporated in a poly( $(\mathrm{D}, \mathrm{L}$-lactide)-coated implant accelerates fracture healing in rats. Acta Orthop 2008, 79(5):717-725.

35. Maritz FJ, Conradie MM, Hulley PA, Gopal R, Hough S: Effect of statins on bone mineral density and bone histomorphometry in rodents. Arterioscler Thromb Vasc Biol 2001, 21(10):1636-1641.

36. Mukozawa A, Ueki K, Marukawa K, Okabe K, Moroi A, Nakagawa K: Bone healing of critical-sized nasal defects in rabbits by statins in two different carriers. Clin Oral Implants Res 2011, 22(11):1327-1335.

37. Cottrell JA, Vales FM, Schachter D, Wadsworth S, Gundlapalli R, Kapadia R, O'Connor JP: Osteogenic activity of locally applied small molecule drugs in a rat femur defect model. J Biomed Biotechnol 2010, 2010:597641.

38. Piskin E, Isoglu IA, Bolgen N, Vargel I, Griffiths S, Cavusoglu T, Korkusuz P, Guzel E, Cartmell S: In vivo performance of simvastatin-loaded electrospun spiral-wound polycaprolactone scaffolds in reconstruction of cranial bone defects in the rat model. J Biomed Mater Res A 2009, 90(4):1137-1151.

39. Thillemann TM, Pedersen AB, Mehnert F, Johnsen SP, Soballe $K$ : The risk of revision after primary total hip arthroplasty among statin users: a nationwide population-based nested case-control study. J Bone Joint Surg Am 2010, 92(5):1063-1072.

40. Patil S, Holt G, Raby N, McLellan AR, Smith K, O'Kane S, Beastall G, Crossan JF: Prospective, double blind, randomized, controlled trial of simvastatin in human fracture healing. J Orthop Res 2009, 27(3):281-285.

41. Hendriksen CF: Refinement, reduction, and replacement of animal use for regulatory testing: current best scientific practices for the evaluation of safety and potency of biologicals. ILAR J 2002, 43(Suppl):S43-48.

42. Back DA, Pauly S, Rommel L, Haas NP, Schmidmaier G, Wildemann B, Greiner SH: Effect of local zoledronate on implant osseointegration in a rat model. BMC Musculoskelet Disord 2011, 13:42.

doi:10.1186/1471-2474-13-208

Cite this article as: Pauly et al:: Influence of Statins locally applied from orthopedic implants on osseous integration. BMC Musculoskeletal

Disorders 2012 13:208.

\section{Submit your next manuscript to BioMed Central and take full advantage of:}

- Convenient online submission

- Thorough peer review

- No space constraints or color figure charges

- Immediate publication on acceptance

- Inclusion in PubMed, CAS, Scopus and Google Scholar

- Research which is freely available for redistribution 